\title{
Functional Endoscopic Sinus Surgery and Conventional Surgery in the Management of Chronic Sinusitis
}

\author{
Mohammod Jamal Hossain ${ }^{1}$, Morshed Alam², Masroor Rahman ${ }^{3}$, Mohammad Idris Ali4 , SM Sarwar ${ }^{5}$
}

\begin{abstract}
Background \& objective: The interest in functional endoscopic sinus surgery (FESS) in the management of chronic sinusitis is increasing day by day. The proponents of FESS for the treatment of chronic sinusitis claim that it is superior to conventional sinus surgery in the management of the disease, but there are limited studies addressing the issue. The present study was undertaken to make a comparative evaluation between FESS and conventional surgery in the treatment of chronic sinusitis.

Materials \& Methods: This prospective study was conducted between October 2005 to March 2006 in the Department of ENT and Head-Neck Surgery, Bangabandhu Sheikh Mujib Medical University (BSMMU), and Dhaka Medical College Hospital (DMCH), Dhaka. A total of 60 patients of chronic sinusitis with failed conservative treatment or chronic sinusitis with polyps admitted for surgical treatment were included. Selected patients irrespective of age and sex were randomly assigned to either FESS $(n=30)$ or conventional surgery $(n=30)$ followed by respective interventions. Baseline clinical characteristics, image findings and outcome variables were studied.
\end{abstract}

Result: Majority of the patients (around 70\%) in either group was in their second and third decades of life. Males were a bit higher in the FESS group. Nasal obstruction was the predominant complaints $(75 \%)$ followed by nasal discharge $(68.3 \%)$ and headache $(66.7 \%)$. X-ray of paranasal sinuses showed opacity in maxillary antrum and nasal fossa in $90 \%$ and mucosal thickening in maxillary antrum in $58.3 \%$ cases. CT scan showed isodense shadow in ethmoid region and nasal fossa (86.7\%) with blocked osteomeatal complex (OMC) on both sides (73.3\%) and mucosal thickening in maxillary antrum (46.7\%). The indications for FESS were chronic sinusitis with ethmoidal polyp (73.3\%), while that for conventional surgery was chronic sinusitis alone $(56.7 \%)$. Majority $(83.3 \%)$ of the FESS group and two-thirds $(66.7 \%)$ of the conventional group had unilateral operation. Most (90\%) of the FESS group required nasal or antral packing during procedure than that of the conventional group $(43.3 \%)(p<0.001)$. Complete recovery was significantly higher in the former group $(70 \%)$ than that in the latter group $(40 \%)(p=0.047)$. Shorter hospital stay (up to 2 days) was observed in majority of the former group patients $(0.001)$. In terms of complications, periorbital oedema was appreciably lower and numbness of the cheek was completely absent in FESS group than those in the Conventional group ( $<0.001$ and $p=0.005$ respectively).

Conclusion: Functional endoscopic sinus surgery offers higher success and lower morbidity than conventional surgery in the management of chronic sinusitis with or without polyp. However, proper training is mandatory to acquire proficiency in FESS.

Key words: Functional endoscopic sinus surgery (FESS), conventional surgery and chronic sinusitis.

\section{INTRODUCTION}

Sinusitis remains one of the most overlooked and misunderstood problem in clinical practice. Incorrect diagnosis and treatment of sinusitis lead to chronic sinusitis, aggravation of symptoms as well as complications such as intracranial and intraorbital infection, which can be quite serious. ${ }^{1}$ For normal physiologic function

\footnotetext{
Authors' Information:

${ }^{1}$ Dr. Mohammod Jamal Hossain, Jr. Consultant (ENT), Chandanaish Health Complex, Chittagong.

${ }^{2}$ Dr. MD Morshed Alam, Medical Officer, ENT Department, BSMMU, Dhaka.

${ }^{3}$ Dr. Masroor Rahman, Research Assistant, ENT Department, BSMMU, Dhaka.

${ }^{4}$ Dr. Mohammad Idris Ali, Medical Officer, ENT Department, BSMMU, Dhaka.

${ }^{5}$ Dr. SM Sarwar, Associate Consultant, Specialist ENT Hospital of SAHIC, Mohakhali, Dhaka.
}

Address of Correspondance: Dr. Mohammod Jamal Hossain, Jr. Consultant (ENT), Chandanaish Health Complex, Chittagong. Cell: +880 1711-581607, Email: drjamal78@yahoo.com 
of paranasal sinuses, the ostia must be patent, the cilia must be functioning effectively and the secretion should be normal. Retention of secretion in the paranasal sinuses can be due to one or more of the following: obstruction of ostia, reduction in the number or impaired function of cilia or overproduction or change in the viscosity of secretion. ${ }^{2}$ Diagnosis of chronic sinusitis can be made on clinical history, physical and radiological examination. Proper treatment of chronic sinusitis is essential to maintain normal life. The treatment may be medical and surgical. While medical treatment includes antibiotic, decongestant, steroid and analgesic, surgical treatment is functional or radical. ${ }^{3}$

Previously it was believed that mucosa had become chronically inflamed and irreversibly damaged and as such it had to be removed. This was the rationale behind conventional surgery like the Caldwell-Luc surgical technique, which involves the removal of diseased lining of the maxillary antrum and antral washout. Similarly the external surgical approaches to ethmoid and frontal sinuses were designed for "radical operation" in which disease was completely cleared. These procedures left scars and caused significant morbidity. Caldwell-Luc procedure also caused numbness of teeth and cheek. ${ }^{4}$

To overcome these demerits and limitations of Caldwell-Luc procedure, Functional Endoscopic Sinus Surgery (FESS) emerged. The rationale behind the FESS is that localized pathology in the osteomeatal complex blocks the ostia and leads to inflammation in the dependent sinuses. The surgical intervention in this procedure is designed to remove the osteomeatal blockage and restore normal sinuses ventilation and mucociliary function. FESS, like all minimal invasive surgery is designed to have an excellent outcome with minimal patient discomfort. As mentioned, the main advantage of FESS compared with conventional surgery is that it is less invasive and scars with damage to the nerve supply of the teeth are avoided. The use of endoscope permits a better view of surgical field leading to meticulous cleaning of the surgical cavity with consequent lower rate of complication. ${ }^{5}$ Functional endoscopic sinus surgery can be performed under both local or general anesthesia. However, Local anesthesia with deep sedation is preferable because sensory information remains intact along the periorbital and skull base region. Other beneficial effects of local anesthesia are minimum bleeding during operation, less hospital stay and less cost.

Because of the above merits, the interest in endoscopic sinus surgery is increasing day by day. The surgeons who employ FESS for the treatment of chronic sinusitis in Bangladesh generally claim that it is superior to conventional sinus surgery in the management of the disease, ${ }^{4}$ but there is paucity of studies regarding its efficacy on chronic sinusitis. That purpose the present study was undertaken to make a comparative evaluation between FESS and conventional surgery in the treatment of chronic sinusitis.

\section{Materials \& Methods}

This prospective study was conducted over a period of 6 months between October 2005 to March 2006 in the Department of ENT and HeadNeck Surgery, Bangabandhu Sheikh Mujib Medical University (BSMMU), Dhaka and Dhaka Medical College and Hospital (DMCH). A total of 60 patients of chronic sinusitis resistant to conservative treatment or chronic sinusitis with polyps admitted for surgical treatment were included in the study. The patients of any age and either sex were randomly assigned to either FESS $(n=30)$ or conventional surgery $(n=30)$ and received their respective interventions. Baseline clinical characteristics, image findings and outcome variables were studied. Data were processed and analysed using software SPSS (Statistical Package for Social Sciences) version 16.0. The test statistics used to analyse the data were descriptive statistics, Chi-square $\left(c^{2}\right)$ or Fisher's Exact Test with level of significance being set at 0.05 and $p$-value $<0.05$ was considered as significant. 


\section{Operative procedure}

After applying suitable vasoconstrictor in the nasal cavity, the middle turbinate (the most important landmark for FESS), was first identified as at this level lies the uncinate process. First uncinectomy was done exposing the ethmoidal bullae. Then anterior and posterior group of cells were removed. Sphenoid sinus was exposed for removal of disease, if present. Natural ostium of maxillary sinus was inspected, and if found obstructed, was opened, cleared off the pathology and widened. The frontal recess was inspected and opened when there is frontal disease. The concha bullosa of the middle turbinate was removed to deal with disease and to enlarge the OMC.

\section{RESULT}

Majority of the patients (66.7\% in FESS and $73.3 \%$ in Conventional group) in either group was in the age range of $21-40$ years ( $p=$ 0.547). In the FESS group males outnumbered the females, but in the conventional group malefemale distribution was almost equal $(p=0.602)$ (Table I). Nasal obstruction was the predominant complaints $(75 \%)$ of the study patients followed by nasal discharge $(68.3 \%)$ and headache $(66.7 \%)$. The next common complaints were sneezing $(48.3 \%)$, hyposmia $(45 \%)$, recurrent

\begin{tabular}{|c|c|c|c|}
\hline \multirow[b]{2}{*}{ Demographic characteristics ${ }^{*}$} & \multicolumn{2}{|c|}{ Group } & \multirow[b]{2}{*}{ p-value } \\
\hline & $\begin{array}{l}\text { FESS } \\
(n=30)\end{array}$ & $\begin{array}{c}\text { Conventional } \\
(n=30)\end{array}$ & \\
\hline \multicolumn{4}{|l|}{ Age } \\
\hline$£ 20$ & $6(20.0)$ & $3(10.0)$ & \multirow{3}{*}{0.547} \\
\hline $21-40$ & $20(66.7)$ & $22(73.3)$ & \\
\hline$>40$ & $4(13.3)$ & $5(16.7)$ & \\
\hline \multicolumn{4}{|l|}{ Sex } \\
\hline Male & $18(60.0)$ & $16(53.3)$ & \multirow{2}{*}{0.602} \\
\hline Female & $12(40.0)$ & $14(46.8)$ & \\
\hline
\end{tabular}

Figures in the parentheses indicate corresponding \%;

* Chi-squared Test $\left(\mathrm{c}^{2}\right)$ was done to analyz the data. sore throat $(43.3 \%)$ and snoring $(41.3 \%)$. In Xray of paranasal sinuses, over $90 \%$ exhibited opacity in maxillary antrum and nasal fossa and $58.3 \%$ mucosal thickening in maxillary antrum. CT scan showed isodense shadow in ethmoid region and nasal fossa $(86.7 \%)$ with blocked OMC on both sides (73.3\%) and mucosal thickening in maxillary antrum $(46.7 \%)$ (Table II). The indications for FESS was chronic sinusitis with ethmoidal polyp (73.3\%), while that for conventional surgery was chronic sinusitis alone

TABLE II. Distribution of respondents by presenting symptom $(n=60)$

$\begin{array}{lcc}\text { Presenting symptom } & \text { Frequency } & \text { Percentage } \\ \text { Complaints } & & \\ \text { Nasal obstruction } & 45 & 75.0 \\ \text { Nasal Discharge } & 41 & 68.3 \\ \text { Headache } & 40 & 66.7 \\ \text { Sneezing } & 29 & 48.3 \\ \text { Hyposmia } & 27 & 45.0 \\ \text { Recurrent sore throat } & 23 & 43.3 \\ \text { Snoring } & 25 & 41.3 \\ \text { Facial pain } & 9 & 15.0 \\ \text { Nasal bleeding } & 2 & 3.3\end{array}$

Findings in X-ray paranasal sinuses OM view

Opacity in maxillary antrum

and nasal fossa

55

91.7

Mucosal thickening in

maxillary antrum

35

58.3

Septal deviation

18.3

Antral polyp

11

8.33

\section{Findings of CT Scan}

Isodense shadow in ethmoid

region and nasal fossa $\quad 13 \quad 86.7$

Blocked OMC (both sides) $\quad 11 \quad 73.3$

Mucosal thickening in maxillary antrum $13 \quad 46.7$

$\begin{array}{lll}\text { Paradoxical middle turbinate } & 1 & 6.7\end{array}$

$\begin{array}{lll}\text { Agger nasi puneumatization } & 1 & 6.7\end{array}$

Concha bullosa

1

6.7

*Total will not correspond to $100 \%$ for multiple responses 
in $17(56.7 \%)$, chronic sinusitis with antrochoanal polyp in $10(33.3 \%)$ and chronic sinusitis with ethmoidal polyp in $3(10 \%)$ cases (Table III). Most $(83.3 \%)$ of the patients in FESS group and two-thirds $(66.7 \%)$ of the conventional group had unilateral operation (Table IV). Ninety percent of the FESS group required nasal or antral packing during procedure as compared to $43.3 \%$ of the Conventional group $(p<0.001)$. Majority $(90 \%)$ of the FESS group had shorter hospital stay (up to 2 days) as opposed to $50 \%$ of the Conventional group $(p=0.001)$. Complete recovery was significantly higher in the former group (70\%) than that in the latter group (40\%) $(p=0.047)$. In terms of complications following intervention, periorbital oedema was appreciably lower in FESS group $(6.7 \%)$ than that in the conventional group $(56.7 \%)(p<0.001)$. Numbness of the cheek was completely absent in the former group compared to $23.3 \%$ in the latter group $(p=0.005)$ (Table $V)$.

$\begin{aligned} & \text { TABLE III. Distribution of study patients by their } \\ & \text { indications for surgical treatment }\end{aligned}$
$\begin{array}{llll} & \text { Group } \\ \text { Indications* } & \text { FESS Conventional p-value } \\ & (\mathbf{n = 3 0 )} \quad(\mathbf{n = 3 0 )}\end{array}$
$\begin{array}{llll}\text { Chr. sinusitis with ethmoidal polyp } & 22(73.3) & 3(10.0) \\ \text { Chr. sinusitis with antrochoanal polyp } & 5(16.7) & 10(33.3) & <0.001 \\ \text { Chr. sinusitis } & 3(10.0) & 17(56.7)\end{array}$

Figures in the parentheses indicate corresponding \%;

* Chi-squared Test $\left(\mathrm{c}^{2}\right)$ was done to analyze the data.

\begin{tabular}{|c|c|c|c|}
\hline \multirow[b]{2}{*}{ Site of operation* } & \multicolumn{2}{|c|}{ Group } & \multirow[b]{2}{*}{ p-value } \\
\hline & $\begin{array}{c}\text { FESS } \\
(n=30)\end{array}$ & $\begin{array}{c}\text { Conventional } \\
(n=30)\end{array}$ & \\
\hline Unilateral & $25(83.3)$ & $20(66.7)$ & 0.136 \\
\hline Bilateral & $5(16.7)$ & $10(33.3)$ & \\
\hline
\end{tabular}

Figures in the parentheses indicate corresponding \%;

*Chi-squared Test $\left(\mathrm{c}^{2}\right)$ was done to analyze the data.

\begin{tabular}{|c|c|c|c|}
\hline \multirow[b]{2}{*}{ Outcome* } & \multicolumn{2}{|c|}{ Group } & \multirow[b]{2}{*}{ p-value } \\
\hline & $\begin{array}{c}\text { FESS } \\
(n=30)\end{array}$ & $\begin{array}{l}\text { Conventional } \\
(n=30)\end{array}$ & \\
\hline $\begin{array}{l}\text { Need of nasal and antral } \\
\text { packing during procedure } \\
\text { Duration of hospital stay }\end{array}$ & $27(90.0)$ & $13(43.3)$ & $<0.001$ \\
\hline Up to 2 days & $27(90.0)$ & $15(50.0)$ & 0.001 \\
\hline$>2$ days & $3(10.0)$ & $15(50.0)$ & \\
\hline \multicolumn{4}{|l|}{ Outcome of surgery } \\
\hline Completely recovery & $21(70.0)$ & $12(40.0)$ & \\
\hline Partial recovery & $4(13.3)$ & $5(16.7)$ & 0.047 \\
\hline No recovery & $5(16.7)$ & $13(43.3)$ & \\
\hline \multicolumn{4}{|l|}{ Complications } \\
\hline Haemorrhage & $6(20.0)$ & $9(30.0)$ & 0.371 \\
\hline Periorbital oedema & $2(6.7)$ & $17(56.7)$ & $<0.001$ \\
\hline Ecchymoses of eye & $1(3.3)$ & $3(10.0)$ & 0.301 \\
\hline Crusting & $13(43.3)$ & $9(30.0)$ & 0.284 \\
\hline Synechiae & $4(13.3)$ & $6(20.0)$ & 0.488 \\
\hline Infection & $1(3.3)$ & $3(10.0)$ & 0.301 \\
\hline Numbness of cheek & $0(0.0)$ & $7(23.3)$ & 0.005 \\
\hline
\end{tabular}

Figures in the parentheses indicate corresponding \%; *Chi-squared Test $\left(\mathrm{c}^{2}\right)$ was done to analyze the data.

\section{Discussion}

The present study was done at BSMMU and Dhaka Medical College Hospital where both conventional surgery and FESS are regularly practised for the management of sinonasal diseases. Majority of the patients $(66.7 \%$ in FESS and $73.3 \%$ in conventional group) in the present study ranged from 21-40 years indicating that sinusitis is a disease of young and early middle aged folks which is quite consistent with the findings of Venkatachalam (over $70 \%$ were in age group 21-40 years). ${ }^{6}$ A male predominance was observed $(56 \%)$ in the study which compares with other studies. 7,8

Clinical evaluation revealed that nasal obstruction is the predominant complaint $(75 \%)$ followed by nasal discharge $(68.3 \%)$, headache $(66.7 \%)$, 
sneezing $(48.3 \%)$, hyposmia $(45 \%)$, recurrent sore throat $(43.3 \%)$ and snoring $(41.3 \%)$. These findings are consistent with findings of Rice. ${ }^{9} \mathrm{X}$ ray of paranasal sinuses showed opacity in maxillary antrum and nasal fossa in $90 \%$ cases and mucosal thickening in maxillary antrum in $58.3 \%$ cases. This result contrasts with other study where opacity in antrum was found in $100 \%$ cases, mucosal thickening in $42.8 \%$ cases and septal deviation in $18.6 \%$ cases. ${ }^{10}$ Plain Xray paranasal sinuses is not very informative for FESS but it is less expensive, can be done in the most centres and gives us guideline to perform other investigations such as CT scan. In this study, out of 60 patients preoperative CT scan was done in $15(25 \%)$ cases. Of them $86.7 \%$ showed isodense shadow in ethmoid region and nasal fossa. Blocked OMC on both sides and mucosal thickening in maxillary antrum were observed in $73.3 \%$ and $46.7 \%$ cases respectively. This results are inconsistent with other studies, $6,11,12$ Lund et al ${ }^{12}$ showed concha bullosa in $30 \%$, everted uncinate process $21 \%$, paradoxical middle turbinates $26 \%$, Haller (intraorbital) cells $15 \%$, Aggar nasi pneumatization $42 \%$ and Onodi cells in $12 \%$ cases.

The major indication for FESS was chronic sinusitis with ethmoidal polyp (73.3\%), while that for conventional surgery was chronic sinusitis alone $(56.7 \%)$, chronic sinusitis with antrochoanal polyp (33.3\%) and chronic sinusitis with ethmoidal polyp (10\%). In this study $70 \%$ patients in FESS group were operated under general anaesthesia. Local anaesthesia was given in rest $30 \%$ cases. However, reverse is the case in conventional surgery where $21(70 \%)$ cases were operated under local anaesthesia and the rest $9(30 \%)$ under general anaesthesia. This result is consistent with other studies. 7,13 Local anaesthesia is usually less risky because of less bleeding, less chance of orbital and intracranial complications, for the skull base and periorbital area are highly pain sensitive.

In FESS, unilateral procedure was done in majority $(83.3 \%)$ of the cases and bilateral in
$16.7 \%$ cases. In conventional surgery, unilateral procedure was done in two-third $(66.7 \%)$ of the cases and bilateral in one-third $(33.33 \%)$ of the cases. In terms of outcome, FESS was considered superior, for $70 \%$ of this group experienced complete recovery compared to $40 \%$ of the conventional group. This is similar to the findings of Drake-Lee study, ${ }^{14}$ but inconsistent with the findings of other studies. ${ }^{10,15,16}$ Postoperative complications like periorbital oedema, haemorrhage, synaechiae were also much lower in the former group. Numbness of the cheek was completely absent in the former group compared to $23.3 \%$ in the later group. No life threatening complications such as CSF leak, orbital injury, blindness was noted in either group. Complications in other similar studies were reported to range from $9-29 \%$. Gross et al reported $9 \%$ complication rate out of 123 cases. ${ }^{13}$ Stankiewicz ${ }^{17}$ reported $29 \%$ complications in 90 patients operated upon, with 7 major and 19 minor complications. Schaefer ${ }^{18}$ reported $14 \%$ minor and no major complications. Stammberger ${ }^{19}$ reported two cases of CSF leak and no other major complications in 4000 cases. Besides, in majority (90\%) of the FESS group, the duration of hospital stay was 1-2 days. But in conventional group $50 \%$ had duration of 1 -2 days. In FESS, out of 24 patients with nasal polyp there was no recurrence but in conventional surgery out of 13 patients with nasal polyp 2 recurred with recurrence rate being $6.7 \%$.

So it is clear from the above discussion that FESS offers higher success and lower morbidity than conventional surgery (like antral washout, intranasal antrostomy, Caldwell-Luc operation, ethmoidectomy etc. Functional endoscopic sinus surgery which offers clear illumination of the sinonasal cavity, a prerequisite to deal with diseased tissues while preserving normal healthy structures. Most often surgery can be safely and effectively done under local anaesthesia. 
However, proper training in the anatomy by cadaveric dissection is mandatory to acquire proficiency in functional endoscopic sinus surgery.

\section{REFERENCES}

1. Venkatachalam VP, Jain A. Comparative evaluation of functional endoscopic sinus surgery and conventional surgery in the management of chronic sinusitis. JAMA 2002;100:1-5.

2. Naumann HH. Pathologische Anatomie der chronischen Rhinitis und Sinusitis. Proceedings VIII International Congress of Oto-Rhino-Laryngology Tokyo. International Congress Series Nr. 113. AmsterdamNew York: Excerpta Medica Foundation; 1965. P. 80.

3. Stammberger $\mathrm{H}$. Endoscopic and radiologic diagnosis. In: Stammberger $\mathrm{H}$, editor. Functional Endoscopic Sinus Surgery: The Messerklinger Technique. 1st ed. Philadelphia, Pa, USA: BC Decker; 1991. p. 145-273.

4. Slack R, Bates G. Functional endoscopic sinus surgery. Am Fam Physi 1998;1-11.

5. Gunkel AR, Freysinger W, Martin A, Völklein C, Bale RJ, Vogele M, Thumfart WF. Three-dimensional imageguided endonasal surgery with a microdebrider. Laryngoscope 1997;107(6):834-38.

6. Venkatachalam VP, Anurag. Comparative evaluation of Functional Endoscopic Sinus surgery and conventional surgery In management of chronic sinusitis. IIMA 2002;100(2):1.

7. Alam M. et al. Functional endoscopic sinus surgery (FESS) - Our experience at BSMMU. Bangladesh J Otorhinolaryngol 2003;4:11-14.

8. Shah NJ. Functional Endoscopic Sinus Surgery. Bombay Hospital and Medical Research Centre, Mumbai. Special Issue on Sinusitis \& It's Management. Bombay Hospital Journal [Internet]. 1999 [cited 2014 Jun 27];41(4). Available from: http://www.bhj.org.in/journal/1999_4104_oct99/sp_659.htm
9. Rice DH. Endoscopic sinus surgery: results at 2 year follow up. Otolaryngol Head Neck Surgery 1989;101:476-77.

10. Levine HL. Functional endoscopic sinus surgery: Evaluation, surgery and follow up of 250 patients. Laryngoscope $1990 ; 100: 79-84$.

11. Arild D. Functional endoscopic sinus surgery on a day case outpatient basis. Clin Otolaryngol 1992;17:473-77.

12. Lund YJ, Savy L, Loyd G. Imaging for endoscopic sinus surgery in adults. The Journal of Laryngology and Otology 2000;114:395-97.

13. Gross RD, Sheridan MF, and Burgess LP. Endoscopic sinus surgery complications in residency. Laryngoscope 1997; 107:1080-1085.

14. Drake-Lee AB. Nasal polyps. In: Kerr AG, Mackay AS, Bull TR, editors. Scott-Brown's Otolaryngology. $6^{\text {th }}$ ed. Vol. 4. Rhinology, Oxford: Butterworth-Heinneman; 1997. 4/10/1-16.

15. Wignad ME, Hosemann WG. Results of endoscopic sinus surgery of the paranasal sinuses and anterior skull base. Journal of Otololaryngology 1991;20:385-90.

16. Smith LF, Brindley PC. Indications, evaluation, complications and results of functional endoscopic sinus surgery in 200 patients. Otolaryngol Head Neck Surg 1993;108(6):688-96.

17. Stankiewicz JA, Maywood IL. Complications of endoscopic intranasal ethmoidectomy. Laryngoscope 1987;97:1270-73.

18. Schaefer SD, Manning S, Close LG. Endoscopic paranasal sinus surgery: indications and considerations. Laryngoscope 1989;99:1-5.

19. Stammberger H, Wolf G. Headaches \& Sinus disease. The endoscopic approach. Ann Otol Rhinol Laryngol 1989;97:3-23. 